\title{
Dios en la presencialidad histórica
}

\author{
The Prensence of God in History
}

\author{
Juan García Cobo \\ Facultad de Teología San Isidoro de Sevilla \\ casacomun@icloud.com \\ ID ORCID 0000-0002-8873-9699
}

Resumen: El dinamismo soberano del amor marca la pauta afectiva de la mirada de Dios que adquiere consistencia en la historia y se realiza presencia en humanidad. Jesús de Nazaret, encarnación de Dios muestra al hombre concreto y actual la entrañable afectividad del Padre Dios y pone rostro comunitario al dominio del amor. Consecuente con la «trama de estimulación económica» emprendida, y sabedor de que el hombre es el mejor hacer de la personalidad de Dios, Jesús concentra en el hombre el destino preferente de su afecto auto-comunicativo, y en clave profundamente relacional.

Para poder comprender el estilo de esta dinámica afectiva del estar presencial del Padre en su Hijo, el hombre ha de dejarse encontrar por el poder de seducción del afecto más fundamental que Jesucristo ofrece y hace posible a la manera que el hombre mejor accede a los secretos de Dios: «intimación» de un corazón «empalabrado» por la riqueza del amor más entregado donde lo encuentra, lo relaciona y lo identifica por el Espíritu. La persona de Jesús es el hombre nuevo que resitúa al hombre en la esperanza que recrea. Sólo Él manifiesta el hombre al propio hombre y le descubre plenamente la grandeza de su vocación. Lo fundamental y definitivo para la vida del creyente gira en torno al abrigo acontecido que abraza esta experiencia original cristiana, y que desde entonces se proyecta presencia afectiva, incansable y testimonial a través de los tiempos.

Palabras Clave: Presencia histórica, mirada de Dios.

Abstract: The sovereign dynamism of love sets the affective pattern of God's gaze, which acquires consistency in history and is real presence in humanity. Jesus of Nazareth , incarnation of God, shows the concrete and current man affection of the Father God and puts a comunal face to the domain of love. Consistent with «the plot of economic stimulation» undertaken and aware that man is the best doing of the personality of God, Jesus concentrates in man the preferential destiny of his communicative affection, and in a deeply relational key.

In order to understand the style of this affective dynamism of the presence of the Father in his Son, man has to allow himself be found by the seductive power of the most fundamental affection that Jesus Christ offers and makes possible in the way that man best can access the secrets of God: "intimación" (the process of intimate) of a heart"empalabrado" (in Word) for the wealth of the most devoted love where it finds it, relates it and identifies it by the Spirit. 
The image, the person of Jesus is the new man who restores man in the hope that he recreates. Only He reveals man to man himself and fully reveals to himself the greatness of his vocation.

The fundamental and definitive thing for the life of the believer turns around the shelter ocurred which embraces this original christian experience, and since then an affective, tireless and testimonial presence is projected through the times.

Keywords: Historic Presence, God's Gaze.

\section{ANTECEDENTES DE LA PRESENTACIÓN}

\subsection{Precedencia}

La presencialidad es el marco precedente de situación a la consecuente actuación de Dios en su despliegue continuador. En concreto, este despliegue continuador que hemos denominado 'presencialidad histórica' corresponde al inicio de la intervención directa y personal de Dios en lo humano. Entonces podemos decir que aquella lo es para el hombre porque la historia es siempre «historia del hombre.» Desde esta presencialidad se ubica toda la logística propia del dinamismo comunicativo y el carácter performativo de Dios. Como tal realización divina se desarrolla con la desmesura y la amplificación propias de su acción. Hablamos del estar de Dios mostrándose como lo que es presentándose, es decir, presencia personal manifiesta en su acción segunda desde sí mismo. Lo habíamos apuntado anteriormente. En «La mismidad de Dios», se hace indispensable advertir un cierto cómo o quién de Dios que, en indescriptible y oculto proceso, se hace presente personalmente al hombre que lo capta. El hombre puede saber que la presencialidad de Dios en su quehacer demostrativo es iniciativa soberana, libre y absolutamente innecesaria. Es algo insólito y, precisamente por lo absolutamente innecesario, desborda cualquier proceso de pensamiento. Dios en presencia humana realizando una acción'de sí en el ejercicio del amor. Máximo El Confesor lo expresa así: «En ningún caso se puede alargar el alma hasta el conocimiento de Dios, si Dios no se abaja primero hasta ella para elevarla hasta él. Pues el espiritu humano nunca tendría la fuerza suficiente para correr con el fin de

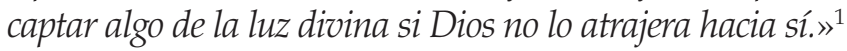

1 Cf. MÁXIMO EL CONFESOR, en: H. U.VON BALTHASAR, Teológica. Verdad de Dios, Encuentro, 1997, p. 103. 
En la experiencia de la presencialidad, lo primero que el hombre advierte de Dios es su iniciativa. Lo segundo es, seguidamente, su despliegue continuador. Y, se mire como se mire, esta iniciativa continuadora de Dios con el mundo y el hombre es como para sumirlo absorto en la más profunda contemplación. La protología, o fe en la creación, encuentra aquí la raíz de su significación. De esta externalización parte todo lo que al hombre se le ofrece inicialmente y que puede conocer referente a Dios. Este conocimiento sólo tornará completo cuando se le otorgue la respuesta que empezó a buscar al ser consciente de su advertencia. Dicho de otra manera, la inteligibilidad de Dios la construye el hombre desde la realización inmanente de Dios que es también atributiva de sí, con manifiesta interacción, incluso proactivamente. Esta externalización de Dios o presencialidad es su primera acción tangible, como una llamada de atención al hombre. Sin necesidad ni condicionante alguno por parte de Dios, el hombre constata la iniciativa divina como causa que, desde el misterioso dinamismo del «en sí» de Dios, se exterioriza y se muestra con incipiente tendencia dialogal. Dios se sitúa en el marco restringido de la limitación humana mostrándose accesible, abordable y en absoluta gratuidad, desde el conjunto total de presencias por las cuales el hombre deduce la suya. Así también, puede inducir la presencia de Dios como absoluto y totalmente Otro, extrayendo saber mediante los sucesos, acontecimientos, eventos y acciones. Y esto en todas las realizaciones del mundo y del hombre. Cada presencia puede considerarse individualmente, o como sistema de presencias. Carece de importancia entrar ahora en los niveles, propiedades, modos, grados, notas, o estructuras en las cuales la presencialidad va desarrollándose. Con una u otra consideración, la dirección que señala la presencialidad tiene sentido focal y su referencia es única. Esta convergencia se adecua al «unum» trascendental. Sin posibilidad de agotamiento de la presencialidad, el hombre se introduce en ella para descubrir y observar el sistema integrador por el cual se sabe presencia imaginada a partir de la propia conciencia de su presencia trascendental. $Y$ no se introduce sin motivo. La presencialidad de Dios antecede y afecta. Y virtud a esta afectación el hombre puede descubrir la iniciativa de Dios. Con todo esto señalamos a Dios, absoluta y totalmente Presencia, llenando y sosteniendo todo el universo, como fuente y origen presencial. Es Dios quien atrae la atención del hombre desde su actuación presencial. Para Dios, la presencialidad creada por Él es el punto de partida desde el cual 
quiere comunicar su existencia al hombre y, por el cual, este se puede entender imagen presencial de Dios y partícipe a título de beneficiario de la creación. Una participación que intuye insuficiente. El hombre es la mejor «huella» de Dios y puede conocerlo desde su propia presencia, con certeza, al percibir la presencialidad y referirla afectado en su presencial trascendentalidad. ${ }^{2}$ Más adelante intentaremos comprender el dinamismo y las consecuencias de esta trazabilidad presencial. Por el momento adelantamos que sin presencia no hay encuentro. No nos encontramos «siendo», sino «estando» presentes en respectividad. Una presencialidad constatable que permite al hombre vivir la experiencia trascendental de «estar en presencia de Dios», incluso desde cualquier realización con la cual Dios quiera concretarse a la particular y única personalización en que consiste y realiza su existencia cada hombre. Hay posibilidad de conocer en la presencialidad, la iniciativa de Dios y su despliegue continuador. El hombre cuenta con todo eso por su capacidad, aunque saberse observador participante no le basta. Dios activa la presencialidad, y comunica la historia del hombre con esta. La iniciativa divina que muestra la presencialidad es el primer acontecer de Dios para el hombre, al cual sumerge en la belleza y la fascinación que lo seduce en la búsqueda, camino hacia la plena manifestación personal de Dios. Cuando el hombre es consciente de este inicio presencial, sabe de una u otra manera que, en esa búsqueda, su búsqueda, le va la vida.

Lo que va a recibir gratuitamente el hombre de Dios son los contenidos y efectos de su personalidad, en términos de afecto.

\subsection{La soberanía del amor}

A Dios le domina el amor. Amor que inicia el dinamismo de Dios. De hecho, Él nos amó primero (cf. 1 Jn 4, 19). Y toda iniciativa de Dios tiende a probar como experiencia viva y fundamental el contenido de esta afirmación. Esta, si se contextualiza con cautela en el ámbito del encuentro interpersonal Dios-hombre no deja indiferente a un lector no neutral de la Palabra. Ni se pasa por alto lo arriesgado de una aseveración que, por razones obvias, resulta doctrinalmente atrevida y que, sin embargo, siendo Dios el amor por excelencia (cf. 1 Jn 4, 8.16) y su dinamismo regido por el afecto, este atrevimiento queda

2 Cf. DH 3004-3005. 
autorizado por el fundamento de la experiencia apostólica transmitida, personal y singularmente vivida del amor cristiano, lo que llamamos la aventura maravillosa que es «la vida del hombre en Cristo» (cf. 2 Co 5, 17). El afecto puede considerarse, desde esta perspectiva, la subsistencia de la acción necesaria de la misma vivencia, es decir, del afectar amando. Porque lo propio de Dios amante es amar con la pasión inherente de un verdadero amor. ${ }^{3}$ Dicho con otras palabras, porque «Dios es amor», su soberanía se extiende en el dominio de suyo que alcanza la realización plenamente afectiva, provocando al hombre con la expropiación de sí mismo, con su desposeimiento (kénosis), asomándose al balcón de la historia del hombre, creado por Él libremente de la nada y constituido en santidad y justicia. ${ }^{4}$ Jesús de Nazaret visibiliza con su presencia el rostro afectuoso de su Padre Dios absolutamente libre, incondicionado, gratuito y manifiesto que remite al hombre al Misterio Comunitario desde su propia carne, salvación y vida para todos, y desde donde la afectiva inter-relación trascendente y humana que se dan cita en Él es clave interpretativa que hace posible el inimaginable acercamiento del hombre al misterio mismo de Dios, un secreto entre amigos que precisa para ser aprehendido de la identificación (Jn 15, 15; 17, 26). El'diálogo orgánico' es relación por excelencia mediante el cual el Padre habla y ama de verdad con el hombre, y comparte el cifrado de su presencia en la persona de su Hijo amado (cf. Jn 1, 17). Con el afecto de Jesús de Nazaret, el hombre aprende la humanidad de la dinámica Comunitaria de Dios. Este amor, y no otro, explica el favor de Dios «gratia» para con el hombre, su iniciativa presencial, la liberación, la alianza con él, la vida en el Espíritu, y la Comunión. Un amor que se concreta personal en respectividad. ${ }^{5}$ Lo intrínseco de este proceso comunicativo estriba en coaptar este amor, y aprehender que el ofrecimiento de Dios al hombre a relacionarse con él como amigo y vivir en santidad y justicia es iniciativa única y afectuosa de Dios que, en la persona de Jesucristo, representa el todo del mundo y del hombre, si este libremente acepta. ${ }^{6}$ El amor de Dios del que estamos hablando es el amor de un Padre entrañable «rajamim», con absoluta independencia de lo que el

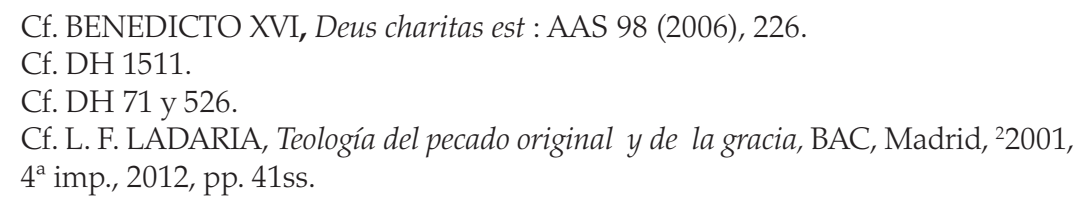


hombre pueda dar u ofrecer, pues, en Dios no hay indigencia alguna, más bien, designio y propósito que hace suya la mejor ofrenda del hombre: «Pues aunque no necesitas nuestras alabanzas, ni nuestras bendiciones te enriquecen, tú inspiras y haces tuya nuestra acción de gracias, para que nos sirva de salvación por Cristo, Señor nuestro.» ${ }^{7}$

Lo verdaderamente esencial y característico que fundamenta y guía las relaciones entre Dios y el hombre es el amor, el impulso motivador, el afecto fundamental, el mismo amor con el que el mundo y el hombre fueron creados, por Él, buenos y libres. Si el hombre quiere saber quién es ha de mirarse dentro y dejarse seducir por el Amor.Y es que cuando el amor de Dios entra en el terreno de las realizaciones, la humana se configura destinataria por excelencia de la donación completa del amor del Padre por medio de su propia concreción en la persona y obra de su Hijo, Jesús de Nazaret. Él es la auto-comunicación de Dios y centro objetivado del alcance pleno de la Revelación por el Espíritu. «Su persona no es otra cosa que amor.» ${ }^{8}$ En la presencialidad histórica la presencia íntima de Dios es el dominio del amor que sustantiva su personalidad: «el ser mismo de Dios es amor.»"

\section{LA MIRADA DE DIOS}

\subsection{Dirección de la mirada presencial}

La perspectiva desde donde se plantea el epígrafe sostiene los contenidos de la antropología teológica, por la cual advertimos la mirada de Dios sobre el hombre. Lo que dice Dios del hombre y cómo lo mira es fundamental a la hora de entender su designio de salvación y vida. G. L. Müller lo expresa con claridad: «la dogmática no puede ya iniciar su discurso directamente de la doctrina sobre Dios.» ${ }^{10} \mathrm{El}$ pensar al hombre como mero objeto de la acción de Dios desvitaliza el contenido de la antropología provocando en el hombre la desafección. ¡Qué extraño resulta un manual de teología dogmática que exprese con fuerza la incontenible alegría de Dios al mirar al hombre! Aún estamos en la búsqueda de dicho manual. El hombre concreto y actual es sujeto llamado

\footnotetext{
CEE., Misal Romano, Prefacio común IV, Libros litúrgicos, 2016, p. 511.

FRANCISCO, Misericordiae vultus, AAS 107 (2015), 404.

Cf. CEC, 221.

Cf. G. L. MÜLLER, Dogmática. Teoría y práctica de la teología, Herder, Barcelona, 2009, p. 105.
} 
a buscar la felicidad en la compañía de su Creador, quien proyecta decididamente todo el dinamismo de su acción, sobre todo, en la cercanía de la historia por amor al hombre. Si el hombre decide mirar su presencia con este mirar de Dios acabará entendiendo quién es, esto es, la presencia valiosísima que Dios empoderó sobre toda la creación. Para eso tiene que estar en condiciones de dejarse encontrar para vivir la medida colmada de su afectividad. Por eso, y desde la experiencia del amor, manifestamos con claridad que la realización más determinante, trasladada desde Dios, dándose a conocer, es aquella que señala hacia dónde preferentemente dirige Dios su ímpetu creador. ${ }^{11}$ Sobre todo, en quien establece su imagen y con quien decide compartir su intimidad en semejanza. El hombre es realización de la 'imagen de Dios' (imagen de la Imagen de Dios), en quien se concreta la mirada afectiva de Dios (cf. Gn 1, 26-27). En su presencialidad, el hombre, es el destinatario preferente y privilegiado hacia donde Dios dirige su presencial afectividad. Aquí entra en juego el mejor hacer de la personalidad de Dios, que es hacer visible al hombre el insondable secreto de su intimidad de forma personalísima. Dios se revela presencia en humanidad. Esta es la abismal diferencia, la misma que existe entre un corazón de piedra y un corazón de carne (cf. Ez 36, 26-28). Ya no hablamos sólo de la «señal en abierto» de Dios, ${ }^{12}$ o del mero descubrir del objeto general de la curiosidad humana en su causalidad, sino de la verificación por excelencia de un Dios relacional en la máxima aproximación personal al hombre: Dios visible de Dios invisible (cf. Col 1, 15). Dios es el absoluta y completamente Otro que en su misterio inicia un camino personal de realizaciones que señala al hombre.

\subsection{La clave hermenéutica de la mirada presencial}

Desde la precedencia y soberanía del amor de Dios, el acompañamiento por este en la situación de alejamiento y caída del hombre,

\footnotetext{
11 Cf. Dei Verbum, AAS 58 (1966), 818.

12 En el ámbito de la transmisión audio-visual, una 'señal en abierto' o 'free to air' (FTA), es susceptible de recepción sin suscripción previa por no estar cifrada. En cambio, una 'señal en cerrado' o 'free to view' (FTV) precisa del código de descifrado para su recepción. Podría preguntarse del por qué de una señal cifrada de Dios para intimar con Él. La respuesta se nos ofrece por la naturaleza trascendente del emisor, señal que necesariamente precisa de un código de traducción y traslación.
} 
en la mayor proximidad de la manifestación histórica y en la tensión de lo ya acontecido pendiente de consumar, la constante en el itinerario presencial de Dios es la 'relacionalidad' (cf. Mc 3, 31-35; Lc 11, 27-28; Mt 6, 9-13; Jn 3, 1-8.) El hombre en relación es clave en nuestra comprensión afectiva del misterio de Dios y del hombre. Nos relacionamos y correspondemos entre nosotros y con Dios. La transversalidad relacional nos compromete para el conocimiento personal de Dios (teo-logía).

Las múltiples tentativas de comunicación divinas que jalonan la «historia salutis», están sustentadas en que el hombre, si quiere, devuelva a Dios la mirada propia de su relación original desde el fin por el cual ha sido realizado humano a imagen y semejanza, y comprenda ante todo qué le une a Él. Dios no rompe su relación con el hombre porque se mira a sí mismo en el hombre. Nunca lo ha hecho y nunca lo hará. Jesús en la cruz, con su sacrificio, habla por sí solo del enamoramiento de su Padre Dios (cf. Jn 15, 13).

Todas las acciones de Dios en la historia gritan al hombre la correspondencia con Él. La relacionalidad construye el ejercicio de la acción de Dios como propiedad esencial. Él ama y tiende la mano al hombre derrochando palabra y vida, empleándose a fondo, hasta el despojo de sí. La relación estipula el máximo común multiplicador del amor en Jesucristo, quien no abarató su esfuerzo y se despojó de lo más valioso de sí para experimentar con sus amigos esta verdad esencial (cf. Mt 23, 8; Jn 15, 4-5.7.9; 17, 11). Dios hace efectivo el aval de su alianza dialogando personalmente con el hombre al que encuentra en la búsqueda que este realiza.

En la constitución del hombre Dios dispuso un terreno competente para que este pudiera acoger su presencia, aprehenderla y dejarse, si quiere, instruir y guiar por ella. Un terreno formativo hecho a medida del misterio del hombre que no entiende de segregaciones y sí de seducción.

El auténtico atractivo primario que el hombre experimenta es el poder de seducción y Dios lo sabe bien. Por eso, el hombre es lugar de presentación de Dios.Y, en precisión, Dios mirándole, hablándole y tocando su corazón. La alianza nueva que en continuidad con la antigua plenifica al hombre es un marco de relación completamente nuevo realizado desde un corazón de carne latiendo en Espíritu. 


\subsection{Motivos del mirar de Dios al hombre}

Encontramos sobradas razones para argumentar la motivación del mirar de Dios (cf. Sal 138; Os 11, 9; etcétera). Lo fundamental y definitivo para la vida del creyente se sitúa desde la experiencia viva de la discontinuidad en continuidad. Si lo pensamos bien, todo conocimiento de Dios y su designio, acogido en la fe, rota en torno a un acontecer decisivo que abraza la experiencia verdaderamente original cristiana, y que desde entonces se proyecta incansable a través de los tiempos. Hay que progresar en la discontinuidad, que representa toda la persona de Jesús de Nazaret en su profundidad afectiva. La experiencia fontal de todo aquel que se ha dejado encontrar por el amor, encuentra en Jesucristo la causa de su afectación. Encuentro que remite a Él como acontecimiento en continuidad de la historia y por el cual alguien empieza a hacerse cristiano. ${ }^{13}$ Jesucristo es respuesta para el hombre. No hablamos del hombre ni de la teología como abstracción, sino de la que se nos ofrece como interpelación de Dios, Padre de Jesús que mira, cara a cara, al 'tú' de cada hombre en sus éxitos y en sus fracasos, en su coherencia y su contradicción, dando sentido a la existencia desde el misterio de perfección humana. La persona de Jesucristo es el hombre nuevo que resitúa al hombre en la esperanza del amor. Jesucristo es el alguien que el hombre oye a veces como anhelo innominado. Él manifiesta el hombre al propio hombre y le descubre plenamente la grandeza de su vocación, por ser el perfecto hombre en quien se dan cita humanidad y divinidad en adecuada entalpía de formación. ${ }^{14}$ Por eso es el Hijo del Hombre. Ciertamente, ningún artista realizó nunca una representación tan perfecta de sí mismo como Dios en Jesús. El «Verbum caro», unido en cierto modo a todo hombre, expresa su voluntad de conducir a este, por el lenguaje de su piel, afectivamente, a la deificación de su carne mientras degusta existente la vida en el Espíritu. Esta es la motivación entrañable de Dios: comunión mientras camina 'estando en su presencia' (cf. Gn 17, 1; Jn 14, 3-4; Hb 6, 19-20). Sin pretender aquí escribir ningún tratado sobre los fundamentos de la fe cristiana, en su pretensión de verdad -teología fundamental- lo cual excede con mucho los límites de esta tesis, conviene traer sintéticamente a estas

\footnotetext{
13 Cf. BENEDICTO XVI, Deus charitas est, AAS, 98 (2006), 217.

14 Cf. Gaudium et spes, AAS 58 (1966) 1042.
} 
páginas la consideración del modelo comunicativo de la revelación, con carácter histórico y sacramental -en palabras y acciones- que apunta decisivamente a la persona de Jesús de Nazaret como mediador único y plenitud de la revelación de Dios. «Porque así quiso Dios invisible, movido de amor, hablar a los hombres como amigos y tratar con ellos para invitarlos y recibirlos en su compañía (...). La verdad profunda de Dios y de la salvación del hombre que transmite dicha revelación, resplandece en Cristo, mediador y plenitud de toda la revelación. ${ }^{15}$ No es decisión del hombre ni mérito suyo. Dios quiere compartir su intimidad con él. Sin embargo, Dios en el hombre con él, y no sin él, «Pues envió a su Hijo, la Palabra eterna, que alumbra a todo hombre, para que habitara entre los hombres y les contara la intimidad de Dios.» ${ }^{16} \mathrm{Y}$, de esta forma, se señala la verdad profunda de la motivación de Dios en Jesucristo. Intimidad de Dios es lo que cuenta el Hijo, lo que ha aprendido de su Padre. Cada vez que el Padre nos mira ve a su Hijo.

\subsection{Finalidad de la mirada de Dios}

Sólo un 'tú', con rostro y corazón verdaderamente humanos, Jesucristo, le muestra al hombre su referencia trascendente. ${ }^{17}$ Los que lo hemos seguido, a través de los tiempos, hemos conocido y vivido las profundidades de un corazón que ama, resolviendo nuestras vidas en su más entrañable intimidad. Así, corroboramos en la Carne de la Salvación ${ }^{18}$ que: «La indestructibilidad corporal es el fin de las obras de Dios.»"

Localizamos en Jesús de Nazaret este designio en la asunción por Dios de la gramática humana. La analogía inmejorable de la materialidad del amor maternal y paternal de Dios que adquiere y asume el dinamismo intrínseco de la afectividad humana, excede los límites formales del misterio, y condesciende en dirección al hombre para luego ascender. Y entendamos bien esto último que resulta

\footnotetext{
Dei Verbum, AAS 12 (1966), 818.

Ibid., 819.

17 Cf. L. F. LADARIA, El Dios vivo y verdadero. El misterio de la Trinidad, Secretariado trinitario, Salamanca, ${ }^{4} 2010$, pp. 70-165. Véase: «La revelación de Dios en la vida de Jesús.»

18 Cf. P. DE NAVASCUÉS BENLLOCH, La Carne de la Salvación, en «Isidorianum», 4.3 (2006), col. Jornadas teológicas, pp. 77 ss. Expresión resumen del contenido de la obra de San Ireneo de Lyon.

19 F. C. OETINGER, en: H. U. VON BALTHASAR, Teológica. Verdad de Dios, Encuentro, 1997, p. 213.
} 
crucial para no equivocar el alcance pleno de la Revelación. Con sólo el movimiento en el sentido único de la divinidad no basta. La humanidad también salva. El despliegue continuador de Dios, descendiendo al hombre, conlleva que al asumir la humanidad está dando valor de salvación a la carne que asciende en Jesucristo. La carne es, pues, sujeto de salvación. De otra manera la salvación sería extrínseca no alcanzando íntegramente al hombre.

La resurrección de Jesús de Nazaret lleva al Padre la humanidad hecha carne, y con ella el tesoro de la afectividad humana. Estamos convencidos de que si no se afirma esto no hay verdadero conocimiento de Dios, o lo que es lo mismo de su «Economía». Por eso, Dios realiza su acción en la presencialidad instando la respuesta afectiva del hombre. Y sólo lo consigue si el hombre constata en la fe que su carne es incorporada al Misterio de Dios.

El hombre llamado a ser como Dios, semejante a Él. Lo finito llamado a lo eterno, a entrar en la comunión de la Trinidad sin saber el por qué, de igual manera como tampoco puede expresar la esencia de Dios, ni concebirlo como inabarcable, por ser Dios «un océano sin riberas» ${ }^{20}$ como gustaba llamarlo De Lubac, o ese «Aquel $»^{21}$ que queda esencialmente fuera de nuestro campo visual por mucho que se extiendan los límites del hombre. Con todo, en lo humano y desde lo humano, orilla cada hombre el borde del Misterio in-espacial y a-temporal.

Todo hombre sea cual sea el medio por el cual recibe la comunicación de Dios es llamado a descubrir su ser hijo de Dios, con carácter personal, desde la Voz autorizada que desborda el mundo y que vive en cada hombre, para toda la Humanidad.

Desde su otorgamiento por entero en su persona, Jesús de Nazaret desvela su identidad comunitaria a sangre y fuego, en Cuerpo y Espíritu. Por todo esto, desde la experiencia que el hombre tiene de la presencialidad de Dios, podemos entender que Dios, por Jesús de Nazaret, con él y en él, se auto-configure para el hombre como «escuela de afectividad», y su finalidad docente se condense en la auto-comunicación. Jesús llevará a término la voluntad de su Padre -también la suya- hasta poner al alcance del hombre todo de Él, humanidad y divinidad, por amor.

\footnotetext{
20 H. DE LUBAC, Por los caminos de Dios, o. c., 103.

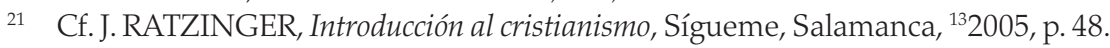


«Comunidad de Personas» es como se nos muestra Dios en su manifestación plena. Lo realiza en Jesucristo y nos enseña por Él el descifrado de la única verdad que el hombre necesita para vivir con referencia y sentido completo. Y lo hará efectivo, si el hombre quiere, en la cordialidad más secreta, donde los amigos lo comparten todo. Amor es lo que el hombre necesita para vivir en plenitud. Además, esta presentación se advierte de imposible contención por su propia consideración trascendente y su dinámica afectiva de carácter migratoria.

Sin entrar en simas fecundas que ocuparon a referentes experimentados como San Agustín de Hipona, Santo Tomás de Aquino, San Francisco de Asís, Santa Teresa de Jesús, San Juan de la Cruz, Hans Balthasar, Henri De Lubac, Santa Teresa de Calcuta, J. L. Ruiz De La Peña, Josep María Coll y, tantos otros, advertimos que el todo de la comprensión de la Revelación de Dios pasa por el encuentro con Jesucristo como una cuestión de afecto.

\section{EL ESTAR PRESENCIAL DE DIOS}

\subsection{La historia como lugar y marco pleno de la presentación}

El espacio global de presentación de Dios por antonomasia es la historia. Parafraseando a René Latourelle «La historia es, pues, el lugar de la revelación [presentación de Dios].» ${ }^{22}$ Dónde, si no, Dios podría hacerse el encontradizo con quien ama. Sólo asomándose por los acantilados del tiempo puede Dios pretender que el hombre se encamine asombrado «a descubrir sus perfecciones invisibles en las obras visibles de la creación» ${ }^{23}$ para que pueda advertir su presencia y dejarse afectar al oír su voz, escuchar su Palabra y tocar enamorado su Carne. Dios es aquel que aprecia la historia y hace posible su interpretación fecunda, dándole sentido y dirección lineal más allá del bucle tiránico y letal de un tiempo circular que hace al hombre prisionero (el tiempo cósmico).

Dios en la historia no comunica especulación alguna, ni está interesado en facilitar al hombre un catálogo de información racionalista. Tampoco un repertorio de comprensión sensiblera de su presencia, en cuanto que pueda ser controlado. De ninguna manera podemos

\footnotetext{
22 R. LATOURELLE, Teología de la Revelación, Sígueme, Salamanca, 122016, p. 436.

23 Ibid., p. 430.
} 
esperar de Dios un compendio de definiciones atributivas sobre su amor o su mismidad. Para Dios, toda su presencialidad se realiza experimentable, se demuestra verificable y es conducida por el ejercicio de su designio de amor pleno, que radicalmente alcanza al hombre y, también, al resto de la creación. Dios quiere presentarse al hombre en cordial y semejante comunicación y lo hace en modo humano.

\subsection{Modo preferencial de presentación}

Uno de los modos explícitamente comunicativo de la radicalidad de Dios dándose a conocer, es la Escritura, donde los aspectos de palabra humana y palabra de Dios no se pueden separar, aunque lo hagamos con utilidad didáctica. Esta utilidad no nos debe confundir. El único Dios que conoce la tradición judeo-cristiana es verificable históricamente en la aproximación desde el testimonio humano de su propia presencialidad. La manera del actuar de Dios, lo que realmente despierta su interés, lo encontramos en la Revelación que no es un tratado científico. Su sistema de auto-comunicación se construye sobre una trama integral de estimulación económica sustentado en el dinamismo interpersonal comunitario de Dios, proyectándose como afecto fundamental subsistente y necesariamente acumulativo.

Lo que conocemos como «historia salutis», contenida en la Escritura, tiene consistencia estructural desde la actitud genuina de las acciones de Dios, actitud que guía la contumacia divina en el afán denodado por no abdicar de su mejor y más lograda manufactura: El hombre. La actitud fundamental de Dios enfrenta su lógica a la humana, en su propio dramatismo, que no es más que un corazón sumergido en soledad. Una actitud, la de Dios, que llama la atención por su persistencia. Nos referimos a la fidelidad como actitud propia y propiedad que entreteje la maltrecha urdimbre humana en la trama divina de su proyección escatológica. Para hacer aceptable al hombre esta «trama de estimulación integral», Dios se muestra abierto en su Palabra, orientando de manera significativa la utilización de antropomorfismos varios. ${ }^{24}$ De entre ellos, más que ninguno, a través de sus expresiones de contenido anímico con el que muestra al hombre

24 Cf. Gn 2, 2.7; 4, 14; 6, 6; 21-22; 3, 8; 21; 7, 16; 8, 21; 11, 5; 38, 7; Ex 6, 6; Num 12, 8; Dt 4, 34; Dt 11, 22; 2 Re 17, 18.23; Os 11, 18; 2 Sam 24, 1; Sal 102, 26; Is 5, 25; $30,27$. 
su actuar apasionado. ${ }^{25}$ No en vano ni por azar, del 'libro' llamado Biblia deducimos el testimonio autorizado por «inspiración» de Dios, humanamente «empalabrado», que no aporta ni crónica histórica ni palabrerías interminables. Este Libro sabe únicamente del interés vital del hombre constituido en santidad y justicia, capacitado inteligente y, sobre todo, caracterizado cordialmente «sentiente». Para Dios, esto anterior, resulta una condición irrenunciable a la hora de trazar su estilo en la tarea de relacionarse con el hombre. Una relación presencial y demostrativa en la historia. Por eso la Escritura -Palabra escrita de Revelación- muestra la centralidad de una característica de Dios: la cordialidad. A la luz de la Escritura, podemos atrevernos a decir de Dios que es'todo corazón', cordialidad verdadera, genuina y auténtica. Palabra y corazón se dan la mano. ${ }^{26} \mathrm{El}$ tablero decisivo donde Dios asume la apuesta más elevada, jamás realizada, es el corazón del hombre. Ahí lanza su comunicado. El hombre cordial en lo mejor de sí mismo: en la fraterna solidaridad, en la entrega, en el sacrificio, etcétera. $Y$ con frecuencia tan volátil y retorcido, como necesitado de afecto (cf. Gn 6, 5-6; Jr 17, 9). De ahí que Dios no sólo se limite a buscar el contacto con el hombre, sino que lo realice afectado, conmovido, y lo radique con su 'gracia', donde el ojo no se arriesga a mirar y el oído no se atreve a oír, con objeto de auto-comunicarse. Al corazón Dios dirige su afecto con su mirada y su palabra, es desde donde Dios construye con el hombre realidades nuevas, y desde donde quiere que el hombre viva mirando y escuchando. ${ }^{27}$ El corazón es lugar de la advertencia, el recibimiento, la acogida, la presentación, la auto-comunicación y la aceptación. Sencillamente, el centro de las

25 Cf. Gn 1, 31; 6, 6. Otros «passim» de Dios se encuentran recogidos y reconocibles en multitud de libros bíblicos: Gn 43, 30; Ex 22, 21; 2 Cro 33, 13; 34, 27; Ez 18, 23; 37, 12-14; Mi 6, 3-8; Mt 11, 25-30; 15, 32ss; Lc 7, 11-17; 19, 41; Jn 11,$33 ; 13,21$; etc...

26 Cf. Sal 94, 7; Jr 31, 33; Ez 36, 26-27; Os 2, 16; Mt 11, 25-26; Mc 7, 6.

27 Cf. DV 12. Partimos del acercamiento a la Biblia desde la convicción de Sagrada Escritura, un hablar de Dios por medio de hombres en lenguaje humano y su inseparable asimilación a Palabra de Dios en palabra humana. Dejamos claro que nuestro objetivo no es un tratamiento exhaustivo y preciso de la Biblia, sino que aprovechamos ciertas ideas y conceptos en los escenarios que esta nos abre para focalizar nuestro interés. Por tanto, solicitamos un cierto margen de benevolencia para asumir que muchas cuestiones las dejamos atrás. Simplemente, nos planteamos cómo la historia es escenario idóneo para que el hombre experimente la Escritura como instrumento de la pedagogía de Dios. 
decisiones humanas. Lo que presupone la fe en Dios no es una inteligencia prodigiosa, ya sea asentimiento categorial a ciertas verdades suprarracionales o, un mero acto del entendimiento ni de la voluntad o del sentimiento. ${ }^{28}$ Más bien requiere de una cordialidad que regala, en la decisión vital más importante, lo más valioso (conocimiento) al desafío confiado del encuentro y, decide experimentar lo íntimo de Dios desde el evento afectivo e incondicionado de Aquél que le mueve a responder. El hombre, entonces, resuelve su existencia en la complacencia y es sustentado así toda la vida. Por eso el Reino de Dios está dentro [corazón] del hombre (cf. Lc 17, 21) y se regala preferentemente a los pobres de espíritu -los cordialmente ricos- (cf. Mt 11, 25). La Palabra de Dios habla al corazón.

\subsection{Significación de Dios dándose a conocer}

No sabiendo cómo, la Eternidad se hizo Tiempo y, desde su plenitud (Lc 1, 26-38; Jn 1, 14; Gal 4, 4), un cómputo nuevo circula desde entonces por la piel de ambos protagonistas -Dios y hombre- citándose para el encuentro. La mirada que Dios traslada en su propia Carne tiene el poder seductor propio de esta convocatoria histórica e incansable. La Revelación, prolongada en multitud de acontecimientos, cuenta a beneficio preferente del hombre. Además, sin pérdidas para él y sin necesidad de inventarios previos. Para Dios no hay esfera de segundos, y sí una retahíla continua de eventos, precedido de sus aconteceres «kairoi» para no dejar encadenado al hombre en un saco de miserias, sino liberarlo mediante una sucesión de ocasiones propicias. Alianza y salvación resumen el contenido fundamental de todo «kairós» de Dios a lo largo de la historia. El «kairós» central y, a la vez punto de encuentro personal es Jesús de Nazaret. Dios es Señor de la historia (cf. Ha 2, 1-4). Cada momento de actuación de Dios es actualización de su misterio presencial en términos de salvación «mirabilia Dei». En la apuesta decidida que Dios realiza a favor del hombre, este siempre sale ganando, incluso, a pesar de su fatiga y desfallecimiento..$^{29} \mathrm{El}$ hombre falla, sucumbe al pecado y se aleja. Sí, es la contradicción más flagrante del hombre buscador de la felicidad (cf. Rom 9, 19). Aún así, cuanto más se aleja el hombre, más empeño

\footnotetext{
28 Cf. W. KASPER, El Dios de Jesucristo, Sígueme, Salamanca, ${ }^{82011, ~ p . ~} 145$.

29 Cf. Gn 1, 31; 3, 15; Is 43, 1-5; Jn 14, 3; Mt 28, 6.
} 
demuestra Dios (cf. Rom 5, 20). Dios se acuerda de su alianza. La fidelidad y misericordia es garantía propia de que Dios cumple siempre sus promesas (cf. Ez 37, 12-14). Por estas propiedades esenciales de Dios (fidelidad y misericordia) el hombre nunca será una causa perdida para Él. Fidelidad que no tiene origen en un contrato de categorías morales que cumplimentar o por el que quiera recibir contraprestación alguna. ${ }^{30}$ La iniciativa de Dios, a impulso de su amor, es gratuita y no está sujeta a nada. Él nunca abdicará del hombre y pretenderá provocar en él una revolución identitaria en la antesala de su profundidad íntima. Allí donde la sospecha del hombre cierra el paso al amor de Dios y le es esquivo. ${ }^{31}$ Allí donde, también, el hombre puede abrir a Dios su estancia presencial (cf. Mt 8, 2-4). Por los efectos que ocasionan esos intentos fallidos de dominio, su inexplicable 'separación', el hombre puede aprender que cuando busca con lucidez y sinceridad identificarse a sí mismo suele encontrar a Dios, que desde siempre ha estado con él, como respuesta ofrecida. "Y tú eras interior a mi más honda interioridad.» $\gg^{32}$

La experiencia personal del Obispo de Hipona como la de tantos otros, nos deja mirar que cuando el hombre permite la afectación homologada de Dios (Jesucristo) entiende que la verdadera humanidad consiste en existir identificado con Él; amado y amando en santidad, y teniéndole en el centro de la propia existencia que no volverá a intentar saborear sin los demás con quienes comparte camino y designio. A lo largo de la historia, muchos otros hombres han acertado en la trazabilidad de este modo interno, íntimo del actuar de Dios como, San John Henry Newman, Charles de Foucauld, Maurice Blondel, Étienne Gilson, Santa Teresa Benedicta De La Cruz, Chiara Lubich, ...

En Jesucristo, el encuentro no sólo tiene el efecto de la homologación asimétrica, sino que realiza la identificación. Con ello, además, adquiere el sentido último de una vida semejante en santidad

30 La gran tentación a la que siempre se encuentra expuesto el hombre es al engaño de creer que se puede uniformar, dominar a Dios (cf. 2 S 7, 5; Is 1, 10-15; Lc 18, 9-14).

31 Cf. Gn 3, 9; 4, 13-15; Sal 94, 14;117; 138, 8; Is 62, 4; Ez 39, 28; Os 11, 8; Mt 13, 53ss.

32 SAN AGUSTÍN, Confesiones, San Pablo, Madrid, ${ }^{2} 1998$, p. 139. 
y justicia. Gracias a este encuentro, nace el hombre nuevo con un corazón encontrado. ${ }^{33}$

\subsection{El hacer docente de Dios: pedagogía, método y estilo}

Gradualmente, Dios lleva a cabo su iniciativa en la historia para hacer adecuado al hombre acoger su Revelación (cf. CEC, 53-55). El progresivo desvelamiento adquiere consistencia en un proceso, en línea recta ascendente, de invitación sostenida y realimentada en la historia y, en un doble nivel de focalización que se inicia de la universal presencialidad a la particular presencia humana, y de lo externo a lo profundo. La significación de este enunciado abarca al hombre y al mundo con la completa y libre disposición de Dios a establecer con el hombre una relación única, personal y permanente (Alianza) por la acción afectiva de Cristo, quien manifiesta el entrañable amor del Padre enseñando y mostrando al hombre la plenitud de la vida en el Espíritu (cf. CEC, 51). La vivencia afectiva de la Comunión en el Amor y que Jesús de Nazaret hace patente, es la forma como Dios lleva al hombre de la mano a la promesa accesible de su identificación. Y lo hace desde la intimidad cordial de ambos protagonistas, haciendo mirar remotamente al hombre, la semejanza y conocimiento pleno de la verdad que está en la interpenetración Dios-hombre.

La pedagogía la implementa desde las inagotables actitudes de paciencia y prudencia hacia quien se acerca respetuoso a ofrecerle su guía. Conforme el proceso de pensamiento en el hombre evoluciona y madura, Dios se hace presente en la historia y da a conocer progresivamente el sentido liberador y salvífico de su presencialidad. La relación de Dios con el hombre, entonces, va extendiéndose en el tiempo y progresa en intensidad. ${ }^{34}$ Esta dinámica reveladora está constantemente actualizada y preparada en el tiempo, anunciando en figura la presencial actividad de Dios en su manifestación plena, y presencia más íntima, Jesucristo (cf. Hb 1, 1-3). Es la continuidad entre alianzas y la discontinuidad de su cumplimiento expresadas en los términos relacionales con que el Eterno ha querido y quiere mostrarse en la mayor aproximación al hombre. La manera de Dios de hacer

\footnotetext{
33 Cf. Jn 10, 30; 17, 21.26; Col 3,1-14, Ef 4,17-23; 5,1-18.

34 Cf. E. GARCÍA LESCÚN, Dios en su revelación, Edit. Agustiniana, Madrid, 2012, pp. 40ss.
} 
inteligible al hombre su presencia se cifra en parámetros de vivencia relacional, incluso en los momentos de mayor encerramiento (cf. Ex $3,14-15) .{ }^{35}$ El de Dios es un hacer cuidadoso por la fragilidad en la cual la desconfianza ha envuelto al hombre como origen de todos los dramas a los que se enfrenta (cf. Gn 3, 1-6; Ex 32, 1ss; Nm 20, 2-13; Dt 1, 29-33; 9, 22-24; Jr 17, 5-8; So 3, 1-2; Mt 8, 23-27; Lc 17, 5-6; Jn 20, 24-29). Dios cuida el acercamiento al hombre, prácticamente lo mima, consciente de su falibilidad y sus limitaciones. El hombre suele encubrir su precariedad con la sospecha. La regulación de este proceso de acercamiento pautado, en el doble nivel de focalización, es coherente con la función moduladora de la pedagogía, desde el inicio de la acción de Dios en la presencialidad, hasta llegar al particular, es decir, la escucha interna, y de lo externo, como la más amplia apertura focal, a lo profundo de las relaciones como referencia original del querer de Dios hacia el hombre a quien creó con ojos para ver desde la oscuridad, y con oídos para oír desde el silencio como capacitaciones del Amor Creador. Los ojos fueron hechos para la luz y los oídos para la palabra. Esto de la pedagogía de Dios en la historia es todo un arte practicado con pericia que pone al alcance del hombre funciones más profundas: mirarlo desde la credibilidad (credere Deo), y escucharlo desde la cordialidad (credere in Deum) para fundar en Él toda la vida en permanente afectación que ama y espera. Es la estructura personal creyente, el concreto sentido de la fe: «Yo creo en ti» (J. Mouroux). Por eso hablar de Dios como objeto de la fe no nos resulta apropiado. La fe reclama existencia en Dios. Podemos advertir, que el quehacer de Dios no es sólo demostrativo e instructor.

El hombre inquiere un punto común de referencia que pueda responder a su necesidad de la forma adecuada. Esta referencialidad se localiza desde la relación homóloga (nada más es homologable al hombre que otro hombre), como destino compatible y único a su condición interpersonal hecha presencialidad. El modo de acceso, la adecuación, es la homologación, que presupone superar el trámite del contacto anecdótico, y el de la superficie sentimental, y entrar de lleno a la aprehensión por el terreno de la similitud. Es parte de nuestro hacer más comunicador y menos cotidiano que se inicia en los sentidos y se realiza trascendental. De otro modo sería imposible obtener

35 A. CORDOVILla (Ed.), La Lógica de la fe. Manual de Teología dogmática, Universidad Pontificia de Comillas, Madrid, 2013, pp. 130-132. 
dicha aprehensión. El hombre no busca limitarse a la experiencia de un conocer externo y precisa un conocer interno del otro, relacional, que satisfaga profundamente la necesidad de auto-comunicación. Sólo con el hombre, el hombre habla, dialoga, se relaciona y se encuentra. Sin los hombres dispuestos no se pronuncian, sólo emiten ruidos. Si el homólogo es Dios en la humanidad de su Hijo, puede el hombre estar seguro de que estará llamando a la puerta sin estridencia para compartir lo suyo más íntimo, dando de sí lo mejor.

El acercamiento cordial, el estilo de Dios, alcanza la genuina búsqueda homologal del hombre y la pretensión de Dios. La cordialidad no se presta al aparecer superficial del cumplimiento. La búsqueda identitaria del hombre, no juega en el terreno del fingimiento, falsedad, o cautela. El corazón no fue creado de piedra. El hombre lo endureció desoyendo la voz de Dios y adentrándose en el sinsentido diabólico del egoísmo, es decir, de la incomunicación. Lo humanamente cordial en la relación, ya sea respecto a otro hombre o a Dios, es sinónimo de compartición. Su pretensión es hacer partícipe al otro del regalo de la intimidad. Intimar es lo que hace Dios con el hombre. Su estilo más personal. La acción se realiza profunda y la hemos denominado «intimación.» ${ }^{36}$

\subsection{El dinamismo de Dios en su estar afectivo}

Con la salvedad ya constatada de que el hombre sólo puede «pensar» a Dios desde su configuración, el hombre puede presentir, conocer y experimentar íntimamente la presencia de Dios, sirviendo de catalizador, a tal finalidad, el afecto. El afecto ejerce influencia y atiende esa percepción cordial y auténtica.

Ciertamente, el estado de conmoción transitorio descrito en el apartado anterior, por efecto de la acción eventual, hace perceptible al hombre el afecto venido de fuera y pone al descubierto una cierta pre-comprensión y presentimiento. El efecto de la conmoción se experimenta y vive internamente de modo cordial y gracias a este efecto el hombre propende y se inclina al encuentro. De otro modo, o con otra intención no tiene significación alguna el deseo incontenible

36 Hacemos notar que tanto el método, el estilo y el dinamismo son básicamente aplicables al encuentro inter-humano y al encuentro entre Dios y el hombre. Si bien, hay que hacer constar la no equivalencia de la segunda relación por una obvia cuestión de asimetría. 
de Dios de auto-comunicarse. Y, además, si no fuese así, necesariamente dejaría sin efecto la dinámica de la reciprocidad afectiva por la cual permite Dios dejarse afectar por quien, inicialmente, ha sido afectado por Él. ${ }^{37}$ La procedencia de esa cierta pre-comprensión y presentimiento de Dios que inicia la posibilidad de correspondencia humana estamos convencidos de que está en el dinamismo de la presencialidad íntima de Dios que mueve. ${ }^{38}$ Es obra de su gracia, activando y trasladando desde el suceso hasta el evento, el afecto que cataliza la intimación y por la cual Dios hace despertar su huella en el hombre. Este lo capta desde su conciencia como intuición fundamental.Y tal intuición se vuelve densa, cuando advertimos que Dios ha querido expresarse con un lenguaje particular para ser mediación del hombre. La gramática orgánica es la auto-manifestación más cercana, entendible y comprensible. En efecto, al encarnarse Dios asume el proceso de humanización (carne en proceso) y, por ello, el hombre tiene acceso a Dios de manera íntima y entrañable. Este acceso de Dios o acortamiento de distancia al hombre hace de este, conductor propio, vehículo característico, e intérprete del misterio del amor de Dios que le permite por el dinamismo del don de la fe captar hasta qué punto Dios, por amor, se implica en la historia y realiza su fin último (Jn 17, 3; 1 Tm 2, 3-4). Con la carne como gramática y su propio desarrollo, Dios apuesta sobre seguro por el hombre y permite a este advertirle en su propio rostro humano. En Jesús de Nazaret, mediación de la inmediatez de su Padre, se hace visible y patente la más perfecta presentación del encuentro con Dios.Y todo esto, ¿para qué? Para que el hombre pueda identificarse con Él, respondiendo al sentido de la propia existencia como persona que se auto-realiza en esa identificación. Con esta, el entendimiento y la comprensión del hombre se completan. El estar presencial de Dios lo lleva a su término el afecto en su realización. Jesús de Nazaret, Presentación de Dios,

37 Consideramos como un error de perspectiva entender que lo que mueve el amor de Dios es la indigencia humana. Sería tanto como pensar que la iniciativa parte del hombre. El amor no admite condición. La desgracia del hombre no es el inicio del amor de Dios. Dios ama al hombre y sale a su encuentro, sea cual sea su condición.

38 Cf. H. U. VON BALTHASAR, Sólo el amor es digno de fe, Sígueme, Salamanca, 22006, p. 71. Balthasar se basa en la «pre-comprensión» incoativa del amor que posee el hombre, considerando el presentimiento como un comienzo de amor en aquel que es amado. 
nos enseñará hasta dónde está dispuesto a llegar el Padre Dios para que el hombre pueda alcanzar lo que busca.Y dejará resuelta la pregunta recurrente para el hombre, a la espera del desenlace. Lo hará a la manera humana del encuentro, como una cuestión de afecto. 
